\title{
РАЗРАБОТКА ИНФОРМАЦИОННОЙ СИСТЕМЫ РАСЧЕТА НЕОБХОДИМОГО КОЛИЧЕСТВА ДЕРЕВОРЕЖУЩЕГО ИНСТРУМЕНТА НА ЛЕСОПИЛЬНЫХ ПРЕДПРИЯТИЯХ
}

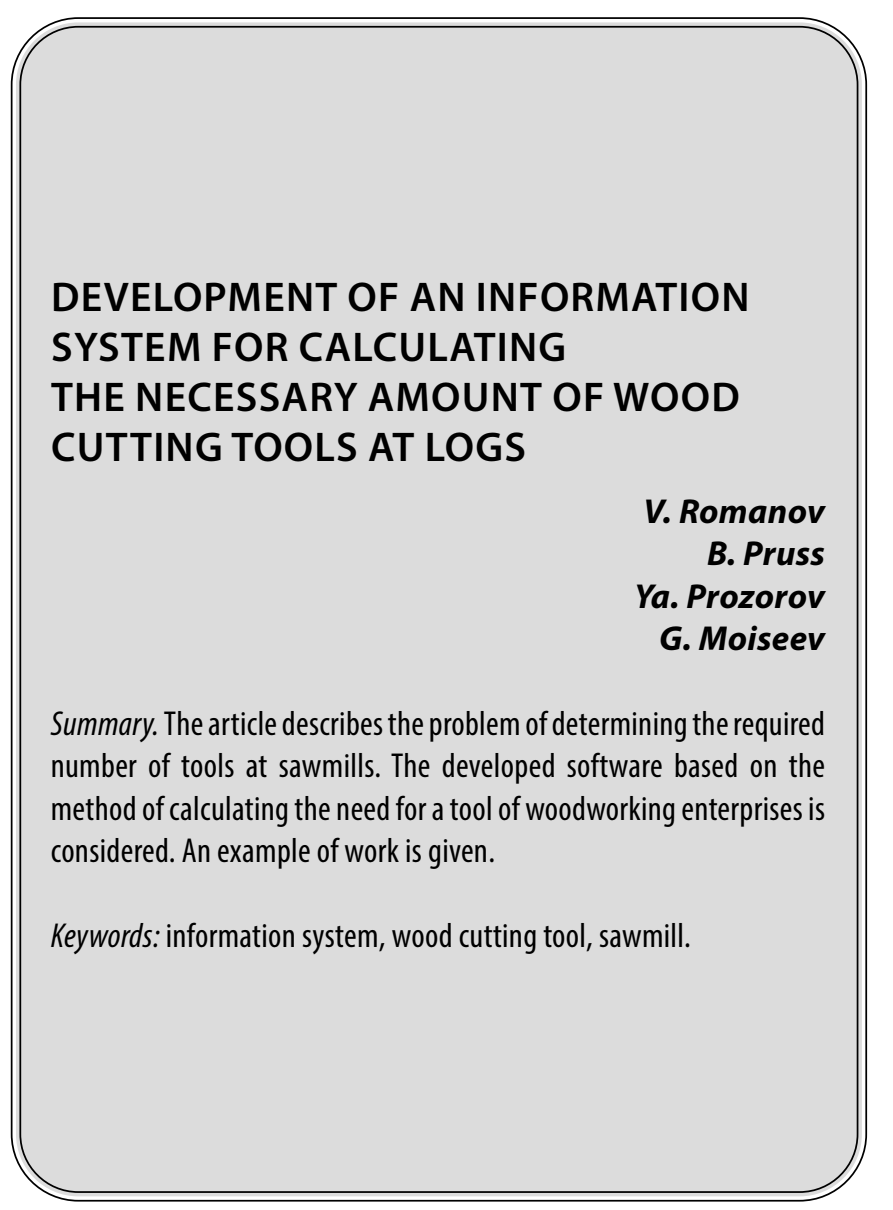

$\ni$ ффективность работы деревообрабатывающих предприятий во многом определяется качеством выпускаемой продукции, которая достигается благодаря правильной настройке и работе режущего инструмента [1]. Следует отметить, что режущий инструмент постоянно выходит из строя и изнашивается при обработке древесины, в зависимости от таких факторов, как виды обрабатываемого материала, загрузка станка, климатических условий его работы и других причин, а величина допустимого износа режущей части инструмента зависит от геометрических параметров инструмента, породы и температурно-влажностного состояния обрабатываемой древесины, режимов резания, требований к точности и чистоте поверхности обработки, технологических особенностей лесопильного производства (число упрягов в смене, наличие бассейна, организация окорки пиловочника и т.д.) [2].
Романов Виктор Александрович

К.т.н., дочент, ФГБОУ ВО «Брянский государственный инженерно-технологический университет», г. Брянск vromanov62@mail.ru

Прусс Борис Наумович

К.т.н., дочент, ФГБОУ ВО «Брянский государственный инженерно-технологический университет», г. Брянск prussbor@gmail.com

Прозоров Ярослав Сергеевич

К.т.н., ФГБОУ ВО «Брянский государственный технический университет», г. Брянск yprozorov@gmail.com

моисеев Григорий Дмитриевич

К.т.н., дочент, ФГБОУ ВО «Брянский государственный инженерно-технологический университет», г. Брянск gregory.d.moiseev@gmail.com

Аннотация. В статье описана задача определения необходимого количества инструмента на лесопильных предприятиях. Рассмотрено разработанное программное обеспечение, основанное на методике расчета потребности в инструменте деревообрабатывающих предприятий. Приведен пример его работы.

Ключевые слова: информационная система, дереворежущий инструмент, лесопильное предприятие.

Исходя из вышеперечисленного своевременный и точный расчет в потребности дереворежущего инструмента способствует повышению качества выпускаемой продукции, а его автоматизация я является актуальной задачей [3].

Автоматизированный расчет в потребности дереворежущего инструмента не только позволит оптимизировать потребности в нем, но и снизит количество ошибок и брака, что приведет к снижению издержек и совершенствованию технологического процесса деревообрабатывающих предприятий, что является важным фактором, особенно если речь идет о промышленных масштабах. Разрабатываемая информационная система [4] расчета потребности деревообрабатывающего инструмента должна включать в себя следующие функции: 


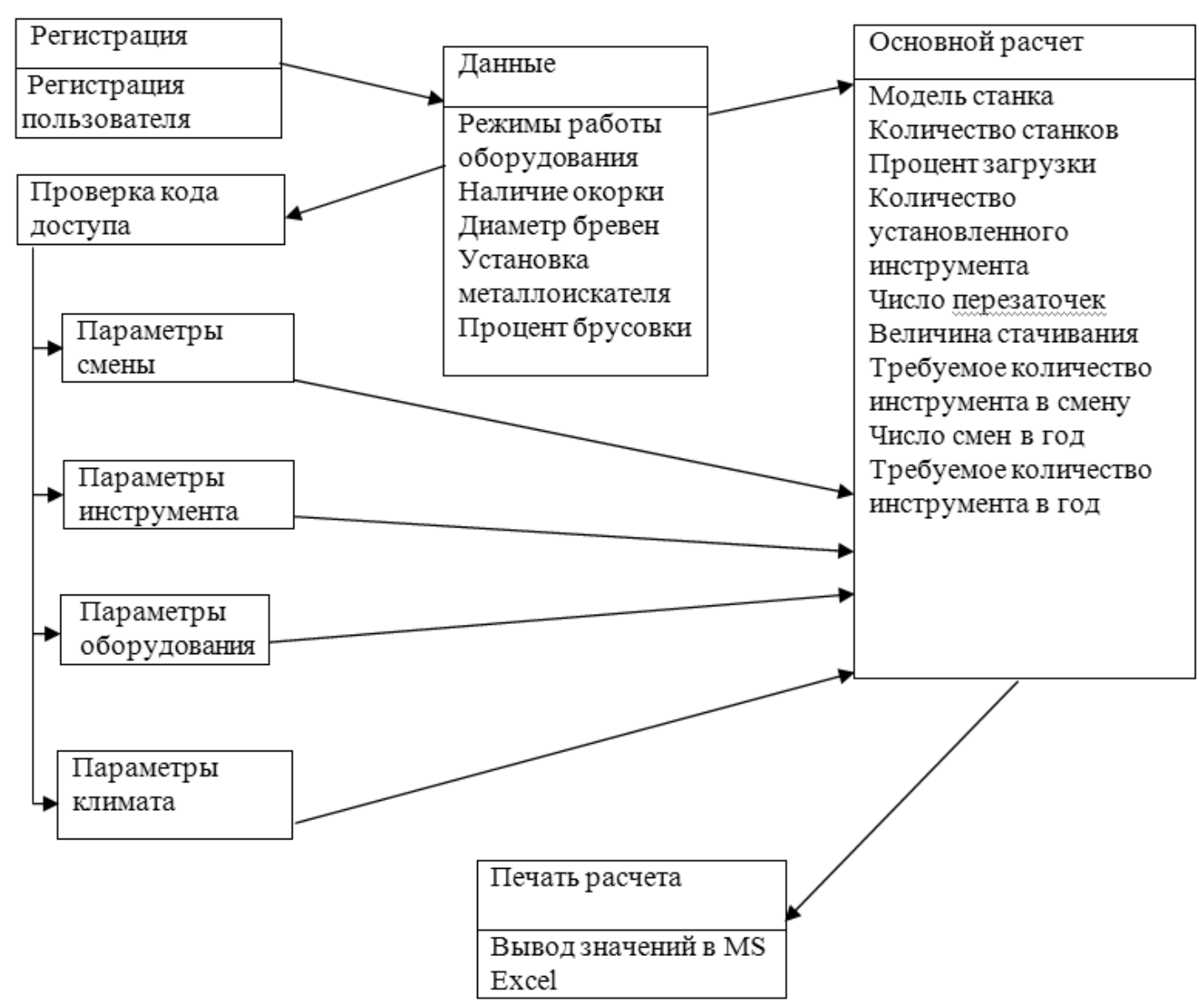

Рис. 1. Схема разрабатываемой информационной системы расчета дереворежущего инструмента

ввод параметров и корректировка применяемого инструмента;

- ввод параметров дереворежущего оборудования;

- ввод видов древесных пород;

- изменение сезонности производства;

- ввод корректных исходных данных;

- защита от ошибок при вводе данных;

- защита от изменения условно постоянной информации;

- изменение величина допустимого стачивания за одну переточку;

- возможность корректировки максимальной величины стачивания инструмента;

- возможность записи в отчет результатов расчета для различных производств;

- составление отчетов в Excel.

Общая схема разрабатываемой информационной системы представлена на рис. 1.

Нами также был проведен подробный анализ деревообрабатывающих предприятий, специализирующихся на производстве пиломатериалов и применяющих различные виды оборудования, в ходе которого установлено, что процесс расчета потребности в дереворежущем инструменте должен состоять из правильного ввода данных, соблюдения правил расчета, а затем должно осуществляться выполнение расчета в потребности дереворежущего инструмента, с учетом загрузки имеющегося оборудования, при этом при некорректном вводе данных расчет осуществляться не должен. Также важным требованием должна быть возможность добавления или удаления нового оборудования лесопильного производства. По окончании расчета должно происходить формирование отчета. Процесс расчета потребности в дереворежущем инструменте представлен на рис. 2.

Для реализации указанных выше функций в разрабатываемой информационной системе [5], нами были отобраны данные из справочной литературы [6], описывающие потребности в инструменте лесопильных предприятий.

На деревообрабатывающих предприятиях потребность $P_{p}$, шт., в режущем инструменте для выполнения 
Таблица 1. Значения коэффициента случайной убыли инструмента

\begin{tabular}{|l|l|}
\hline Оборудование & Коэффициент К \\
\hline Лесопильная рама & $1,50 / 1,30$ \\
Многопильный круглопильный станок & $1,30 / 1,20$ \\
Обрезной станок & 1,25 \\
Торцовочный станок & 1,35 \\
Ребровый станок & 1,10 \\
Рубительная машина & $1,30 / 1,10$ \\
Окорочный станок & 1,20 \\
\hline
\end{tabular}

Примечание. Значения коэффициентов К, приведенные в знаменателе, указаны при использовании в потоке металлоискателей

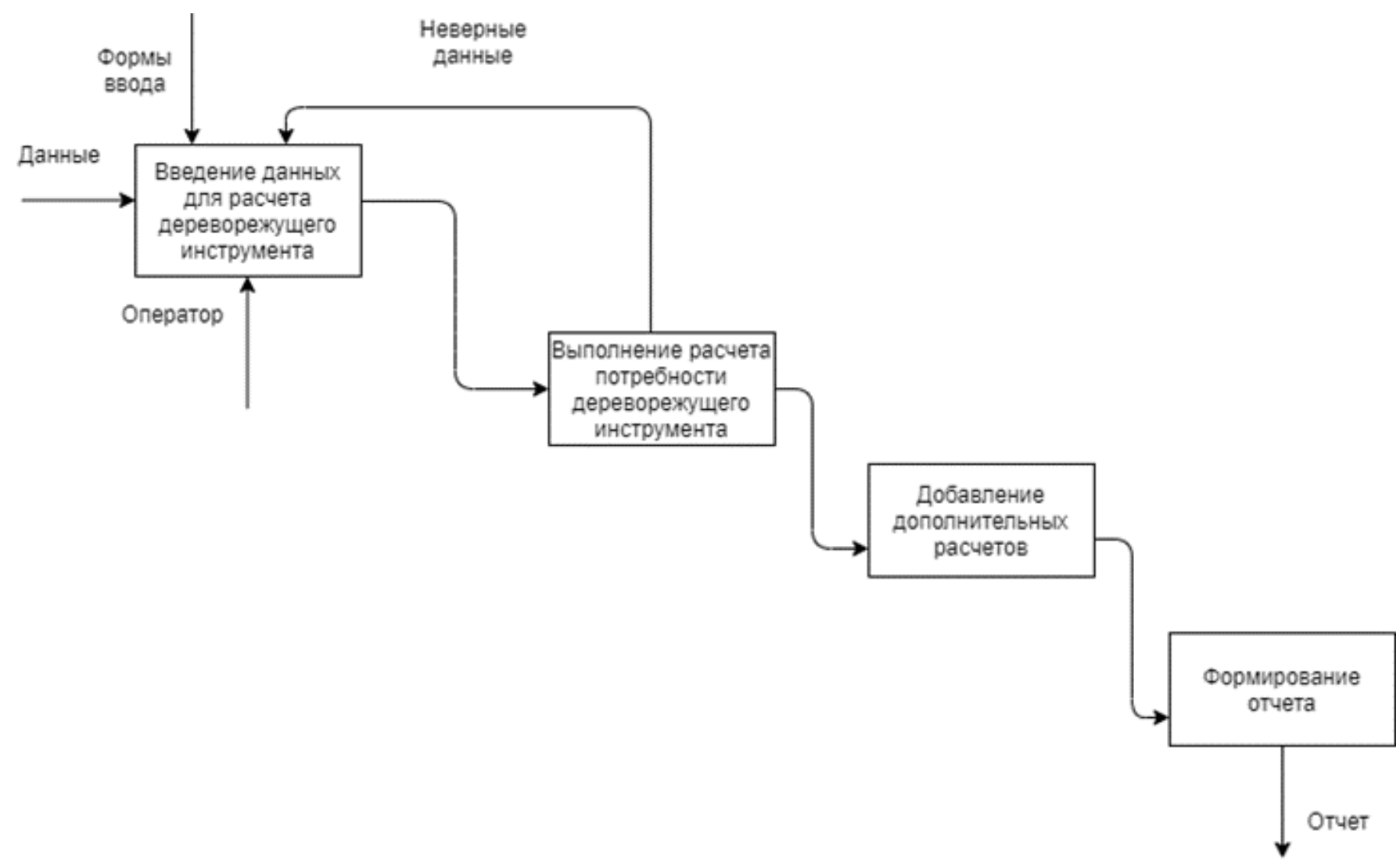

Рис. 2. Процесс расчета потребности дереворежущего инструмента

плана работ по переработке сырья, находят в соответствии с нормами расхода для каждого вида оборудования [7] по формуле

$$
P_{p}=N \cdot W \cdot K,
$$

где $W$ - продолжительность работы применяемого оборудования при выполнении плана работ по переработке сырья, смен;

$K$ - коэффициент, учитывающий случайную убыль инструмента. Значения коэффициента приведены в таблице 1;
$N$ - средневзвешенные годовые нормы расхода инструмента, шт.

Величина стачивания за одну переточку зависит от характера и величины износа режущих граней инструмента, способа и режимов заточки, состояния заточного оборудования и квалификации заточников. Обобщение опыта работы лесопильно-деревообрабатывающих предприятий показало, что в настоящее время заточка инструмента производится примерно при одинаковых режимах независимо от величины нормального износа их режущих граней. Современные 
серийно выпускаемые заточные станки не позволяют нормировать заточку в зависимости от величины износа режущих граней инструмента [8]. Отсутствуют средства объективного контроля степени его затупления в производственных условиях.

Расход рамных пил на плющение и формование с учетом последующей одной переточки, формирующей профиль зуба, зависит преимущественно от состояния плющильно-формовочного оборудования и квалификации работников [9].

В расчетах принята средняя величина расхода пил (по размеру, лимитирующему переточку) на плющение, формование и одну, последующую переточку при использовании серийно выпускаемого станка -модели ПХФ и ручных плющилок, формовок.

Расход короснимателей определяется для наиболее распространенной технологии восстановления режущей их части - наплавки сормайтом № 1. При этом учитывается расход короснимателя на подготовку под наплавку и восстановление наплавкой: среднее количество наплавок по данным производственных наблюдений составляет 5-8 [9].

Значения периода стойкости инструмента между двумя переточками приняты с учетом технологических особенностей лесопильного производства, действующих режимов резания и опыта работы деревообрабатывающих предприятий [8].

Нормы расхода инструмента рассчитываются для каждого типа оборудования. Различают индивидуальные и укрупненные нормы расхода. Первые используют на производстве, вторые-планирующие организации.

Средние значения величин износа инструмента определяются с учетом действующих рекомендаций по подготовке инструмента и режимов резания [7].

Средневзвешенные годовые нормы расхода инструмента N, шт./ станко-смену, определяются по формулам:

- для рамных пил с плющеными зубьями, эксплуатируемых на лесопильных-рамах 1-го и 2-го ряда

$$
\begin{aligned}
& \mathrm{N}=\frac{1}{T_{c} \cdot\left(B_{n}-B_{k}\right)} \cdot\left\{\left(\frac{h_{p}+h_{c} \cdot(y-1)}{y}\right) \cdot\left(a \cdot z_{1}+l \cdot z_{2}\right)+\right. \\
& \left.+\left(\left(h_{t 1} \cdot t_{l}+h_{\dot{\Sigma} 1} \cdot t_{z}\right) \cdot a \cdot z_{1}+\left(h_{t 2} \cdot t_{l}+h_{\dot{\mathrm{z}} 2} \cdot t_{z}\right) \cdot l \cdot z_{2}\right)\right\}
\end{aligned}
$$

- для круглых пил с разведенными зубьями

$$
\mathrm{N}=\frac{2 \cdot \mathrm{z} \cdot\left(\mathrm{h}_{\mathrm{il}} \cdot t_{l}+h_{i z} \cdot t_{z}+h_{c}\right)}{T_{c} \cdot\left(D_{n}-D_{k}\right)} ;
$$

- для ножей рубительных машин

$$
N=\frac{z \cdot\left(h_{i l} \cdot t_{l}+h_{i z} \cdot t_{z}+h_{c}\right)}{\left(T_{l} \cdot t_{l}+T_{z} \cdot t_{z}\right) \cdot\left(B_{n}-B_{k}\right)} ;
$$

- для короснимателей

$$
N=\frac{z \cdot\left(h_{i l} \cdot t_{l}+h_{i z} \cdot t_{z}+h_{c}\right)}{\left(T_{l} \cdot t_{l}+T_{z} \cdot t_{z}\right) \cdot \frac{\left(B_{n}-B_{k}\right) \cdot h_{n}}{h_{p}}}
$$

где $h_{u}$ - изнашивание применяемых инструментов за определенный период стойкости, мм (соответственно индексы при $h_{u}$ означают: 3 - распиловка зимой, $л$ - распиловка летом, а I и II - первые и вторые ряды установки лесопильной рамы) $h_{c}$ - стачивание применяемых инструментов за одну переточку, мм;

$h_{n}$ - расход рамной пилы на плющение и формование с последующей одной переточкой или расход короснимателя при подготовке его под наплавку сормайтом № 1, мм, $h_{n}=2$;

$h_{H}$ - восстановление функциональных характеристик короснимателя наплавлением, мм, $h_{H}=8$;

$Y$ - количество интервалов стойкости рамной пилы между двумя плющениями, $Y=5$;

$B_{H}, B_{K}$ - данные начальной и конечной ширины инструмента, мм;

$D_{H}, D_{K}$-данные начального и конечного диаметра инструмента, мм;

$z$ - количество круглых пил, короснимателей, ножей применяемых в одной единице оборудования, шт.;

$z_{1}, z_{2}$-количество пил в рамах первого и второго рядов, шт.;

$T$ - период стойкости инструмента между переточками в зимнее и летнее время $\left(T_{3}, T_{\Omega}\right)$;

$T_{c}$ - период стойкости инструмента между переточками при $T_{3}=T_{n \text {; }}$

$t_{3,} t_{l}$ - удельные веса времени в зимний и летний периоды работы;

$a, I$ - удельные веса времени работы лесопильных рам при распиловке бревен и брусьев.

Значения периодов стойкости $T_{3} / T_{л}$ в числителе относятся к трехупряжному, а в знаменателе - к двухупряжному режиму работы. При распиловке неокоренного пиловочника хвойных пород на лесопильных рамах 1-го ряда износ рамных пил $h_{m}, h_{u 3}$ необходимо увеличить на $12,5 \%$. При переработке неокоренных отходов лесопиления на технологическую щепу норму расхода рубильных ножей необходимо увеличить на $20 \%$.

Значения ширины рабочей зоны инструмента, числа пил в поставе(z), удельного веса времени в году с отрицательной и положительной температурой воздуха, 
Ż́ Параметры

\begin{tabular}{|r|l|r|r|}
\hline KodPar & NamePar & ZPar & \\
\hline 1 Paсход рамной пилы на плющение, мм & 2 \\
\hline 2 Расход короснимателя при подготовки под наплавку & 2 \\
\hline 3 Восстановление ширины короснимателя наплавкой & 8 \\
\hline 4 Число периодов стойкости рамной пилы между переточками & 5 \\
\hline
\end{tabular}

Рис. 3. Вид формы «Параметры»

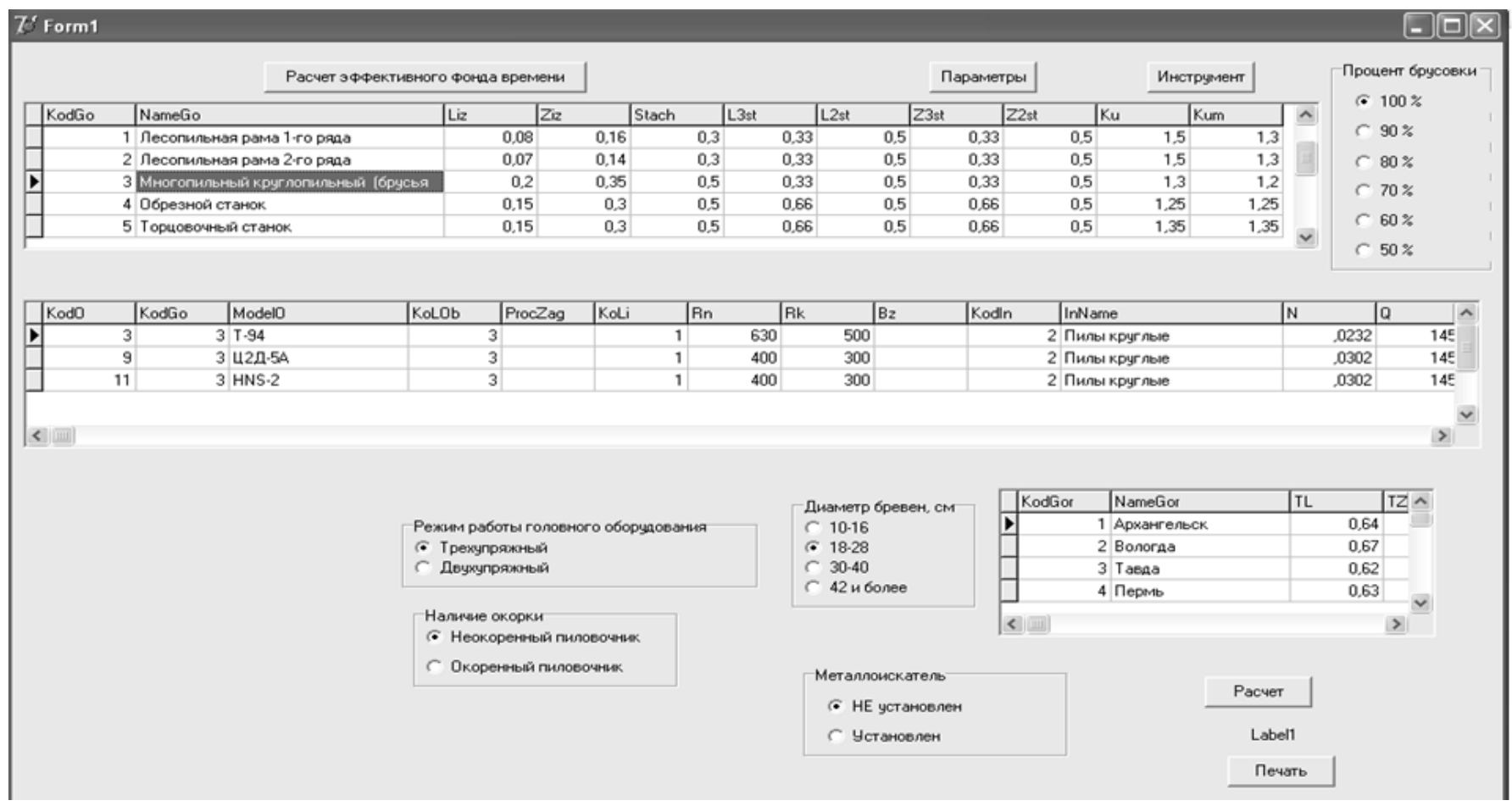

Рис. 4. Вид формы «Основной расчет»

процента брусовки и удельного веса времени работы лесопильных рам при распиловке берется из базы данных, заполненной на основании информации из справочной литературы [6].

Исходя из представленных выше формул $(2,3,4,5)$, выполнение расчета норм расхода инструмента обусловлено большим количеством факторов. Для решения этой задачи необходим поиск в таблицах и работа с данными, что требует большого количества времени, особенно на крупных предприятиях.

Для автоматизации расчетов нами была разработана информационная система, позволяющая моделировать и осуществлять технологический расчет потребностей дереворежущего инструмента, интерфейс которой содержит следующие формы:
- расчет эффективного фонда времени лесопильного оборудования, установленного в цехе, в год;

- параметры инструмента, влияющие на его расход;

- виды дереворежущего инструмента;

- форма для основного расчета.

Рассмотрим некоторые из перечисленных форм.

На рис. 3 представлена форма «Параметры». На ней размещена таблица со списком параметров дереворежущего инструмента и их значениями, взятыми из справочной литературы [6]. Доступ к работе с данной формой возможен только после ввода кода доступа.

На рис. 4 представлена форма «Основной расчет». В верхней части формы расположены: 


\begin{tabular}{|c|c|c|c|c|c|c|c|c|}
\hline 4 & A & B & $\mathrm{C}$ & D & $\mathrm{E}$ & $\mathrm{F}$ & G & $\mathrm{H}$ \\
\hline 1 & Таблица -Г & -Расчет норм рас) & хода режущего инстр & умента и потребнс & ости в нем & & & \\
\hline 2 & оборудование & Количество & Инструмент & Количество & Число & Расход & Коэффиці & Расход \\
\hline 3 & & станков, шт. & & инструмента, шт. & станко-смен & инструмента, & убыли & инструмента, \\
\hline 4 & & & & & & шт./станко-смену & & шт. \\
\hline 5 & РД-50 & 1 & Пилы рамные & 6 & 484 & 0,067392 & 1,5 & 49 \\
\hline 6 & РД-75 & 1 & Пилы рамные & 6 & 484 & 0,053204211 & 1,5 & 39 \\
\hline 7 & РД-110 & 1 & Пилы рамные & 6 & 484 & 0,06318 & 1,5 & 46 \\
\hline 8 & РД-50 & 2 & Пилы рамные & 11 & 968 & 0,107829333 & 1,5 & 157 \\
\hline 9 & РД-75 & 2 & Пилы рамные & 11 & 968 & 0,085128421 & 1,5 & 124 \\
\hline 10 & РД-110 & 2 & Пилы рамные & 11 & 968 & 0,10109 & 1,5 & 147 \\
\hline 11 & T-94 & 3 & Пилы круглые & 1 & 1452 & 0,0232 & 1,3 & 44 \\
\hline 12 & Ц2Д-5А & 3 & Пилы круглые & 1 & 1452 & 0,03016 & 1,3 & 57 \\
\hline 13 & HNS-2 & 3 & Пилы круглые & 1 & 1452 & 0,03016 & 1,3 & 57 \\
\hline 14 & ЦР-4 & 4 & Пилы круглые & 1 & 1936 & 0,02816 & 1,25 & 68 \\
\hline 16 & PC-2 & 2 & Пилы круглые & 2 & 968 & 0,018383893 & 1,1 & 20 \\
\hline 17 & ЦР -4 & 1 & Пилы круглые & 2 & 484 & 0,015742529 & 1,1 & 8 \\
\hline 18 & Норман- 66 & 8 & Ножи рубительных машин & 16 & 3872 & 0,194469766 & 1,3 & 979 \\
\hline 19 & $\mathrm{MPH}-25$ & 1 & Ножи рубительных машин & 16 & 484 & 0,127591707 & 1,3 & 80 \\
\hline 20 & $\mathrm{OK}-66 \mathrm{M}$ & 1 & Коросниматели & 6 & 484 & 0,049947368 & 1,2 & 29 \\
\hline
\end{tabular}

Рис. 5. Вид окна MS Excel с результатами расчета

- кнопки для вызова других форм;

- таблица с нормативными данными для каждой группы оборудования;

- группа переключателей, позволяющих выбрать процент брусовки при раскрое круглых лесоматериалов.

В центре формы размещена таблица, в которую пользователь должен ввести список деревообрабатывающего оборудования, установленного в лесопильном цехе. В данную таблицу вводится:

- модель станка, предварительно выбрав группу оборудования из верхней таблицы;

- количество однотипных станков, установленных в цехе;

- процент загрузки указанного оборудования в год;

- выбирается вид дереворежущего инструмента и вводится количество однотипного инструмента, установленного на данном оборудовании;

- указываются параметры инструмента, например, для круглых пил -диаметр новой пилы и минимальный возможный диаметр пилы после нескольких переточек.
В нижней части формы расположены:

- группы переключателей (для указания режима работы головного оборудования, наличия окорочного станка и металлоискателя перед раскроем пиловочника, среднего диаметра раскраиваемых бревен);

- таблица, позволяющая выбрать климатические параметры в зависимости от территориального место расположения лесопильного цеха;

- кнопка для выполнения расчета;

- кнопка для конвертирования результатов расчета в формат MS Excel (рис. 5) и последующего вывода на печатающее устройство.

Разработанная информационная система автоматизирует решение задачи подбора и потребности в дереворежущем инструменте для лесопильных предприятий, что в свою очередь совершенствует технологический процесс, позволяет внести в него изменения. Также данная информационная система сокращает время расчета и повышает его точность, что приводит к своевременной замене дереворежущего инструмента. Указанные факторы влияют на качество лесопильной продукции.

\section{ЛИТЕРАТУРА}

1. Обеспечение работоспособности рабочих органов и инструментов машин и оборудования лесного комплекса / Заикин А.Н., Меркелов В., Памфилов Е.А., Пыриков П.Г. Известия высших учебных заведений. Лесной журнал. 2010. № 3. -С. 10-14.

2. Меркелов В.М. Технология деревообрабатывающих производств: учебное пособие для студентов высших учебных заведений, обучающихся по направлению 250400 «Технология лесозаготовительных и деревоперерабатывающих производств» специальности 250403 «Технология дерево0бработ- 
ки» / В.М. Меркелов, А.Н. Заикин. - Гос. образовательное учреждение высш. проф. образования Брянская гос. инженерно-технологическая акад., Брянск, 2010.-256 c.

3. Суханов В.Г. Основы резания древесных материалов и конструкции дереворежущего инструмента: учеб. пособие /В.Г. Суханов, В.В. Кишенков.- М.: ГОУ ВПО МГУЛ, 2006. - 199 с.

4. Проектирование информационных систем: учебно-методическое пособие / Сост. Шамсутдинов Т.Ф. Казань: КГАСУ, 2018. - 110 с.

5. Иванов К.К. Проектирование информационных систем / К.К. Иванов. - Текст: непосредственный // Молодой ученый. - 2017. C. 22-24.— URL: https://moluch.ru/archive/153/43309/ (дата обращения: 16.07.2021).

6. Глебов И.Т. Справочник по дереворежущему инструменту: справочник / И.Т. Глебов. - СПб.: Лань, 2020. - 224 с.

7. Зотов Г.А. Дереворежущий инструмент. Конструкция и эксплуатация: учебное пособие / Г.А. Зотов. — СПб.: Лань, 2010.—432 с.

8. Янушкевич, А.А. Технология лесопильного производства: учебник для студентов вузов по спец. «Технология деревообрабатывающих производств», «Машины и оборудование лесного комплекса», «Профессиональное обучение (деревообработка)» / А.А. Янушкевич; Белорусский государственный технологический университет.- Минск: БГТУ, 2010. — 328 с.

9. Особенности исследования изнашивания режущих инструментов для переработки древесных материалов // Памфилов Е.А., Шевелева Е.В./Известия высших учебных заведений. Лесной журнал. 2017. № 6 (360). С. 89-103.

( ) Романов Виктор Александрович ( vromanov62@mail.ru ), Прусс Борис Наумович ( prussbor@gmail.com ),

Прозоров Ярослав Сергеевич ( yprozorov@gmail.com ), Моисеев Григорий Дмитриевич ( gregory.d.moiseev@gmail.com )

Журнал «Современная наука: актуальные проблемы теории и практики»

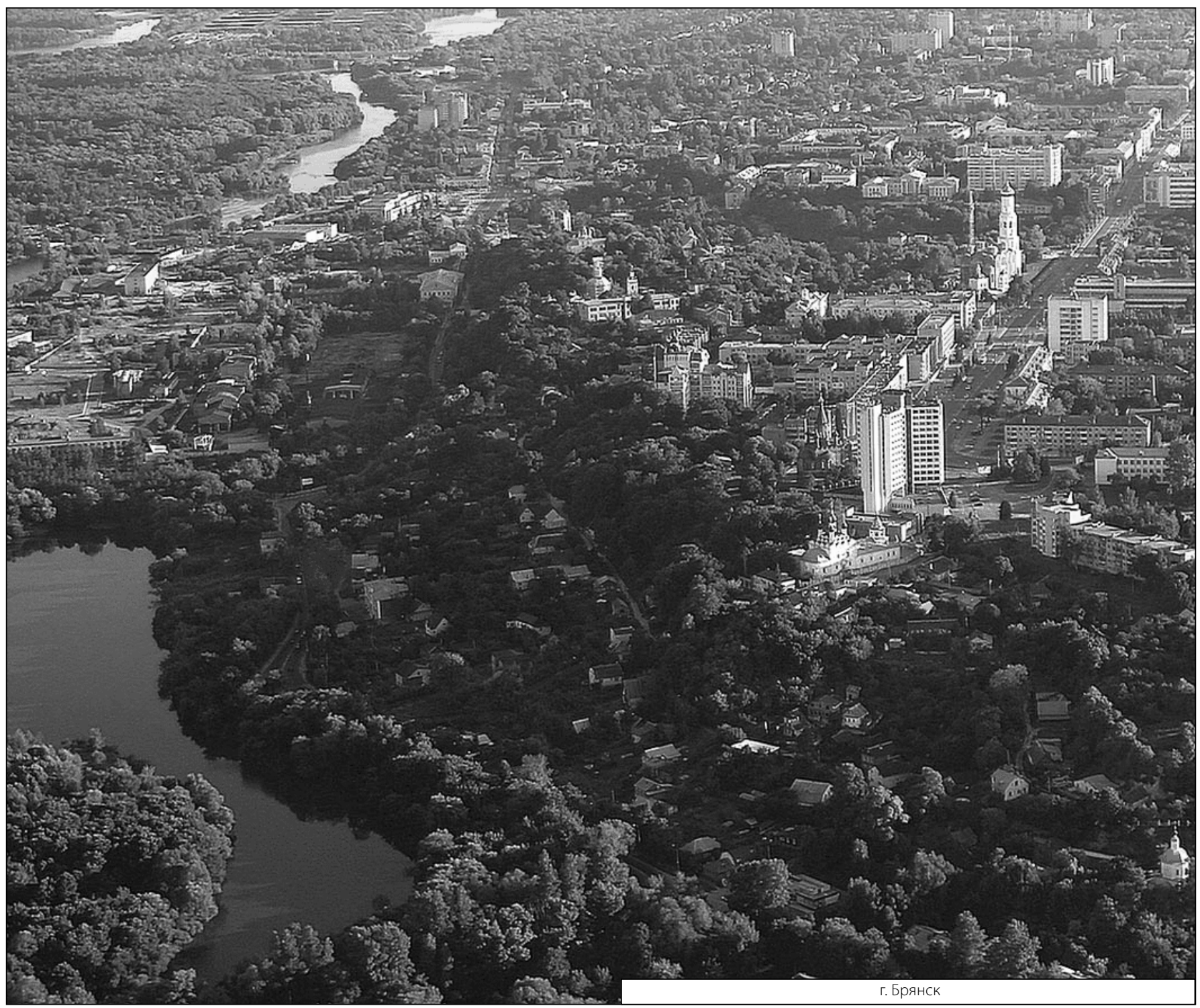

